\title{
ASSESSMENT OF THE IMPACT OF GEOMECHANICAL PARAMETERS VARIABILITY ON UNDERGROUND EXCAVATIONS STABILITY USING RESPONSE SURFACE METHOD
}

\author{
Witold PyTEl, JOANNA ŚWITOŃ \\ KGHM Cuprum Ltd. Research and Development Centre \\ Gen. Wł. Sikorskiego 2-8, 53-659 Wrocław, Poland. \\ E-mail: wpytel@cuprum.wroc.pl; jswiton@cuprum.wroc.pl
}

\begin{abstract}
Recognition of properties of the rock mass surrounding a mineral deposit is particularly important for the mining operations at greater depths. Since the rock mass is usually not homogeneous, and its parameters have characteristics of randomness, underground workings safety issue should always be analysed taking into account the dispersion of the values of these parameters around their mean values. In order to assess the impact of geotechnical parameters uncertainty on the excavation stability one uses the appropriate statistical approach. In this paper, by analysing successive combinations of geomechanical parameters of the rock in the measured range, we examined the effect of their variability on risk of underground excavation instability using response surface method.
\end{abstract}

\section{INTRODUCTION}

As a result of disturbance of the original rock mass balance, stress concentration or part of rock mass relaxation usually is observed, which in turn can lead to rocks overload and formation of failure zones around the excavation. In order to minimize the risk in practice the stability assessment based on deterministic methods is usually carried out on the basis of geological data. Rock mass is the medium of a heterogeneous nature, due to which the process of underground exploitation is connected with complex random phenomena. Therefore, an analysis of the impact of random parameters on the modelled phenomenon should be an essential component of the underground facilities stability assessment. Apart from this issue, you can lose very valuable information about the quality and reliability of the excavation analysed. Inevitable random distribution of the rock mass parameters can have a significant impact on the behaviour of the whole underground structure [6], [7].

There are a number of theoretical works on how to reflect the actual underground conditions through models using the probabilistic methods. In this case, information on the random characteristics of input data is essential. Generally, to describe the geotechnical parameters the normal probability distribution is assumed most frequently [5], [9].

Over the recent year, a few papers concerning the response surface method application in geotechnical problems were published. In these cases the method in question 
was used for soil mechanics assumptions rather than rock mechanics. Zangeneh et al. [15] applied Response Surface Method to Newmark displacement analysis of submarine slopes. Reliability analysis of single piles or pile groups in soils of random parameters using the method considered was of interest, among others, Bauer and Puła [1], [2]. The problem of shallow tunnels in a frictional and/or cohesive soil was presented by Mollon et al. [11]. However, the excavations at a greater depth are exposed to quite different conditions than in shallow openings. Therefore, one must assume a lot of risk factors. Because of the complexity of the phenomenon of underground excavations stability it is hard to determine some adequate criterion for identifying the state of instability [4]. It is proven that from time to time rock mass is stable even though severe damage or local failures have occurred. In most cases, the failure is triggered off in conditions of blasting or seismic activity [14].

Therefore, as the first step of research concerning the identification of adequate way to define the instability state in underground openings and method to work out the general relationship between the geomechanical and mining parameters and stability of underground facilities, we analysed the behaviour of the rock mass around the excavation under condition of changing selected geomechanical parameters and width of the excavation values using Mohr-Coulomb failure criterion. Four selected parameter values were differentiated according to the multiplication rule having the minimum, maximum, and mean value. For calculations the Phase ${ }^{2}$ program was used. The results obtained were used to derive the formula for the underground excavations stability factor in the form of a linear function using a statistical approach based on the response surface methods concept.

\section{ROCK MASS MODEL}

The analysis was conducted on the example of the numerical model of the rock mass in the form of a flat disc with dimensions of $50 \times 50 \mathrm{~m}$. The excavation of a constant height of $4 \mathrm{~m}$ and variable width from $6 \mathrm{~m}$ to $8 \mathrm{~m}$ was located in the rock mass. In order to examine the impact of the individual parameters variability on the rock mass quality, it was considered as the homogeneous medium made of elastic-perfectly plastic material, within which only the values of selected parameters and the width of the excavation are changed. Zero displacement in the vertical and horizontal directions is assumed at all boundaries of the rock mass model under consideration.

It is assumed that the value of the vertical in-situ stress is $24 \mathrm{MPa}$. Horizontal insitu stress was determined as a fraction of the vertical stress value according to adopted for the calculation Poisson's ratio equal to 0.33. Finally, the following in-situ stress values in the field are considered:

- $\sigma_{1}=24 \mathrm{MPa}$,

- $\sigma_{3}=12 \mathrm{MPa}$. 
A desired relationship of stress values was obtained in Phase $^{2}$ by assuming a 90degree angle of maximum horizontal stress relatively to the horizontal direction that the horizontal component of the stress is reduced by a factor of two with respect to the vertical component.

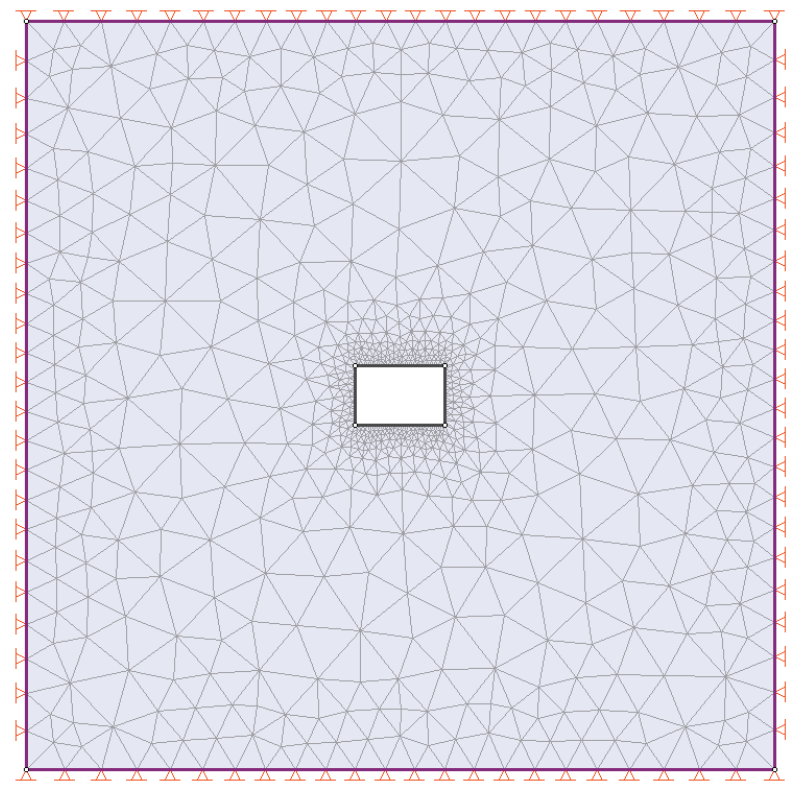

Fig. 1. Rock mass model used for calculation

\section{DEVELOPMENT OF DATA SETS}

The data sets for analysis were developed taking into account the dispersion of the values around the mean value in accordance with the multiplication rule [8]. According to this rule, when the result of the certain calculation may be obtained in the successive steps $k$, with $k_{1}$ results in the first step, $k_{2}$ results in a second step, $k_{n}$ results in the $n$-th step, etc., then the result may be obtained in

$$
N=k_{1} k_{2} \cdots k_{n} \text { ways. }
$$

In this case, the number of steps depends on the number of parameters, and the number of results for each parameter determines the number of variables taken into calculation (mean, minimum, maximum, lower quartile, etc.). Therefore, the above formula would be as follows

$$
N=k^{p}
$$


where

$N$ - number of data sets,

$k$ - number of variables,

$p$ - number of parameters.

According to this principle by assuming the analysis of four random variables with values of minimum, maximum and mean we can get 81 sets of data (see Table 2).

Three uncertain geotechnical parameters and one uncertain parameter associated with the geometry (width of the excavation) were adopted for the analysis. The random parameters values were assumed in accordance with developed connection between mechanical and strength parameters of the rock mass and compressive strength obtained in the laboratory conditions. The parameters listed in Table 1 are assumed as normally distributed.

Table 1

Dispersion of assumed random variables values around their mean value for the range of compressive stress values from 70 to $250 \mathrm{MPa}$ obtained in the laboratory conditions

\begin{tabular}{|c|c|c|c|c|c|c|c|}
\hline \multirow{2}{*}{ Parameter } & \multirow{2}{*}{ Symbol } & \multirow{2}{*}{ Units } & \multicolumn{5}{|c|}{ Value } \\
\cline { 5 - 9 } & & & Min & Max & Mean & $\begin{array}{c}\text { Standard } \\
\text { deviation }\end{array}$ & $\begin{array}{c}\text { Coefficient } \\
\text { of variation }\end{array}$ \\
\hline Angle of friction & $\phi$ & $\circ$ & 30 & 70 & 50 & 16.4 & 0.33 \\
\hline Cohesion & $c$ & $\mathrm{MPa}$ & 3 & 40 & 21.5 & 15.2 & 0.71 \\
\hline Tensile strength & $\sigma_{t}$ & $\mathrm{MPa}$ & 0.1 & 3 & 1.6 & 1.2 & 0.75 \\
\hline Width of excavation & $S$ & $\mathrm{~m}$ & 6 & 8 & 7 & 0.8 & 0.11 \\
\hline
\end{tabular}

Calculations were based on the mean values of the other two parameters: Young's modulus $E_{m}=77500 \mathrm{MPa}$ and Poisson's ratio $v=0.25$.

Table 2 shows established combinations of parameter values.

Table 2

Developed data sets

\begin{tabular}{|c|c|c|c|c|c|c|c|c|c|c|c|c|c|c|}
\hline & $\phi$ & $c$ & $\sigma_{t}$ & $S$ & & $\phi$ & $c$ & $\sigma_{t}$ & $S$ & & $\phi$ & $c$ & $\sigma_{t}$ & $S$ \\
\hline $\mathbf{1}$ & $\mathbf{2}$ & $\mathbf{3}$ & $\mathbf{4}$ & $\mathbf{5}$ & $\mathbf{6}$ & $\mathbf{7}$ & $\mathbf{8}$ & $\mathbf{9}$ & $\mathbf{1 0}$ & $\mathbf{1 1}$ & $\mathbf{1 2}$ & $\mathbf{1 3}$ & $\mathbf{1 4}$ & $\mathbf{1 5}$ \\
\hline Set 1 & 30 & 3 & 0.1 & 6 & Set 28 & 70 & 3 & 0.1 & 6 & Set 55 & 50 & 3 & 0.1 & 6 \\
\hline Set 2 & 30 & 3 & 0.1 & 8 & Set 29 & 70 & 3 & 0.1 & 8 & Set 56 & 50 & 3 & 0.1 & 8 \\
\hline Set 3 & 30 & 3 & 0.1 & 7 & Set 30 & 70 & 3 & 0.1 & 7 & Set 57 & 50 & 3 & 0.1 & 7 \\
\hline Set 4 & 30 & 3 & 3 & 6 & Set 31 & 70 & 3 & 3 & 6 & Set 58 & 50 & 3 & 3 & 6 \\
\hline Set 5 & 30 & 3 & 3 & 8 & Set 32 & 70 & 3 & 3 & 8 & Set 59 & 50 & 3 & 3 & 8 \\
\hline Set 6 & 30 & 3 & 3 & 7 & Set 33 & 70 & 3 & 3 & 7 & Set 60 & 50 & 3 & 3 & 7 \\
\hline Set 7 & 30 & 3 & 1.55 & 6 & Set 34 & 70 & 3 & 1.55 & 6 & Set 61 & 50 & 3 & 1.55 & 6 \\
\hline Set 8 & 30 & 3 & 1.55 & 8 & Set 35 & 70 & 3 & 1.55 & 8 & Set 62 & 50 & 3 & 1.55 & 8 \\
\hline
\end{tabular}




\begin{tabular}{|c|c|c|c|c|c|c|c|c|c|c|c|c|c|c|}
\hline $\mathbf{1}$ & $\mathbf{2}$ & $\mathbf{3}$ & $\mathbf{4}$ & $\mathbf{5}$ & $\mathbf{6}$ & $\mathbf{7}$ & $\mathbf{8}$ & $\mathbf{9}$ & $\mathbf{1 0}$ & $\mathbf{1 1}$ & $\mathbf{1 2}$ & $\mathbf{1 3}$ & $\mathbf{1 4}$ & $\mathbf{1 5}$ \\
\hline Set 9 & 30 & 3 & 1.55 & 7 & Set 36 & 70 & 3 & 1.55 & 7 & Set 63 & 50 & 3 & 1.55 & 7 \\
\hline Set 10 & 30 & 40 & 0.1 & 6 & Set 37 & 70 & 40 & 0.1 & 6 & Set 64 & 50 & 40 & 0.1 & 6 \\
\hline Set 11 & 30 & 40 & 0.1 & 8 & Set 38 & 70 & 40 & 0.1 & 8 & Set 65 & 50 & 40 & 0.1 & 8 \\
\hline Set 12 & 30 & 40 & 0.1 & 7 & Set 39 & 70 & 40 & 0.1 & 7 & Set 66 & 50 & 40 & 0.1 & 7 \\
\hline Set 13 & 30 & 40 & 3 & 6 & Set 40 & 70 & 40 & 3 & 6 & Set 67 & 50 & 40 & 3 & 6 \\
\hline Set 14 & 30 & 40 & 3 & 8 & Set 41 & 70 & 40 & 3 & 8 & Set 68 & 50 & 40 & 3 & 8 \\
\hline Set 15 & 30 & 40 & 3 & 7 & Set 42 & 70 & 40 & 3 & 7 & Set 69 & 50 & 40 & 3 & 7 \\
\hline Set 16 & 30 & 40 & 1.55 & 6 & Set 43 & 70 & 40 & 1.55 & 6 & Set 70 & 50 & 40 & 1.55 & 6 \\
\hline Set 17 & 30 & 40 & 1.55 & 8 & Set 44 & 70 & 40 & 1.55 & 8 & Set 71 & 50 & 40 & 1.55 & 8 \\
\hline Set 18 & 30 & 40 & 1,55 & 7 & Set 45 & 70 & 40 & 1.55 & 7 & Set 72 & 50 & 40 & 1.55 & 7 \\
\hline Set 19 & 30 & 21.5 & 0.1 & 6 & Set 46 & 70 & 21.5 & 0.1 & 6 & Set 73 & 50 & 21,5 & 0.1 & 6 \\
\hline Set 20 & 30 & 21.5 & 0.1 & 8 & Set 47 & 70 & 21.5 & 0.1 & 8 & Set 74 & 50 & 21,5 & 0.1 & 8 \\
\hline Set 21 & 30 & 21.5 & 0.1 & 7 & Set 48 & 70 & 21.5 & 0.1 & 7 & Set 75 & 50 & 21,5 & 0.1 & 7 \\
\hline Set 22 & 30 & 21.5 & 3 & 6 & Set 49 & 70 & 21.5 & 3 & 6 & Set 76 & 50 & 21,5 & 3 & 6 \\
\hline Set 23 & 30 & 21.5 & 3 & 8 & Set 50 & 70 & 21.5 & 3 & 8 & Set 77 & 50 & 21,5 & 3 & 8 \\
\hline Set 24 & 30 & 21.5 & 3 & 7 & Set 51 & 70 & 21.5 & 3 & 7 & Set 78 & 50 & 21,5 & 3 & 7 \\
\hline Set 25 & 30 & 21.5 & 1.55 & 6 & Set 52 & 70 & 21.5 & 1.55 & 6 & Set 79 & 50 & 21,5 & 1.55 & 6 \\
\hline Set 26 & 30 & 21.5 & 1.55 & 8 & Set 53 & 70 & 21.5 & 1.55 & 8 & Set 80 & 50 & 21,5 & 1.55 & 8 \\
\hline Set 27 & 30 & 21.5 & 1.55 & 7 & Set 54 & 70 & 21.5 & 1.55 & 7 & Set 81 & 50 & 21,5 & 1.55 & 7 \\
\hline
\end{tabular}

\section{ANALYSIS OF RESULTS}

Because of the complexity of underground excavations stability problem it is hard to determine the adequate criterion allowing instability state to be accurately identified. In our opinion the most critical parameter in this issue is the range of deformation. One of the possible criterions connected with the amount of failed mesh elements has been tested as a first notwithstanding all its shortcomings. The goal was to check the simplest, not necessarily scientifically justified assumptions concerning the possible criterion which will be able to be used in the future analysis. Because it is strictly dependent on the finite elements mesh this criterion could be applicable only with reservations associated with mesh characteristic. The criterion tested was based on the observed range of deformation (shear and bending) around the excavation according to which the excavation remains stable when the deformation area covering less than 100 finite elements surrounded the excavation (stability factor $W S=1.4$ ) (Fig. 2c), while above 200 elements excavation can lose stability ( $W S=0.5$ ) (Fig. 2a). For values between that range the failure zones due to shear and bending were developed in the rock mass around the excavation, but with a small spatial extent (Fig. 2b). It was concluded that under these conditions only additional risk factors (e.g., seismic) could lead to excavation instability. The following figures show the state of the rock mass around the excavation, depending on the selected parameters indicating stability factor values adopted for further calculations. 


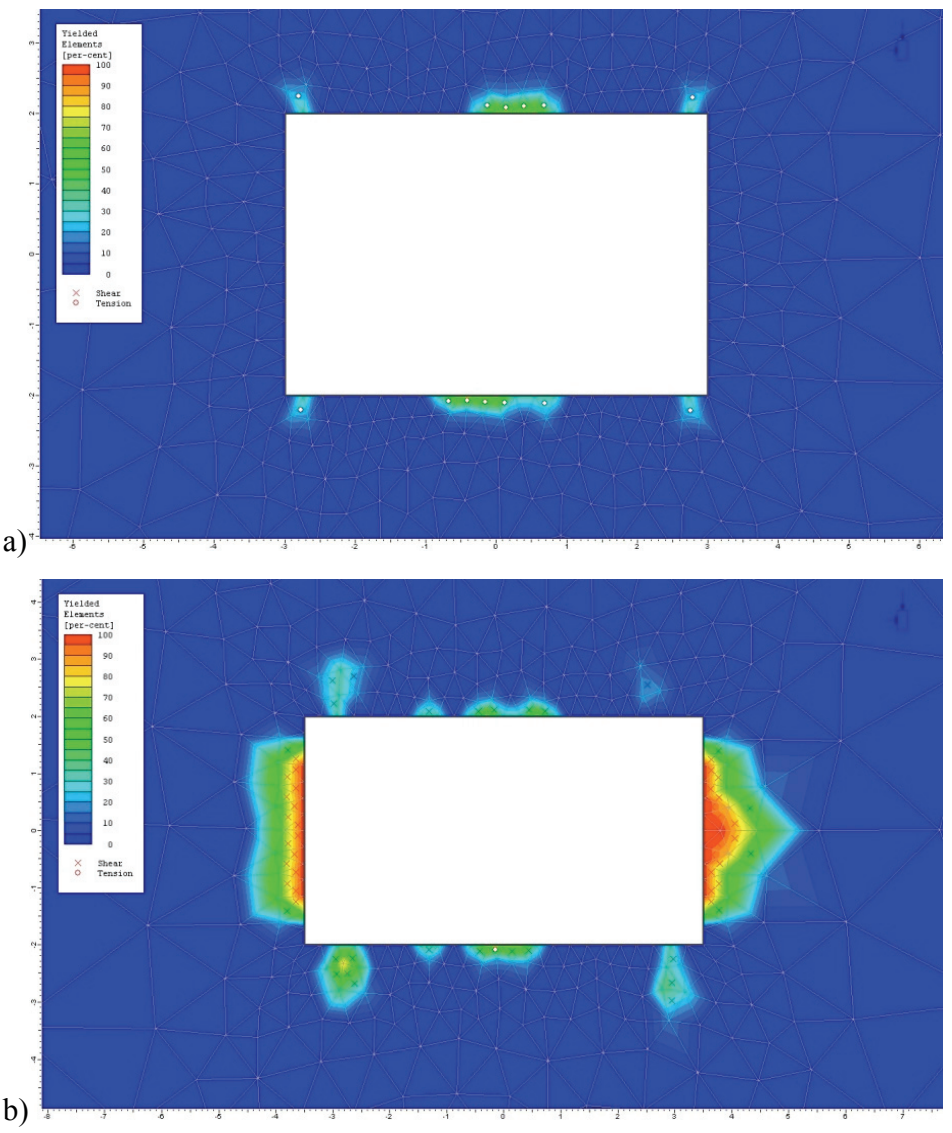

b)

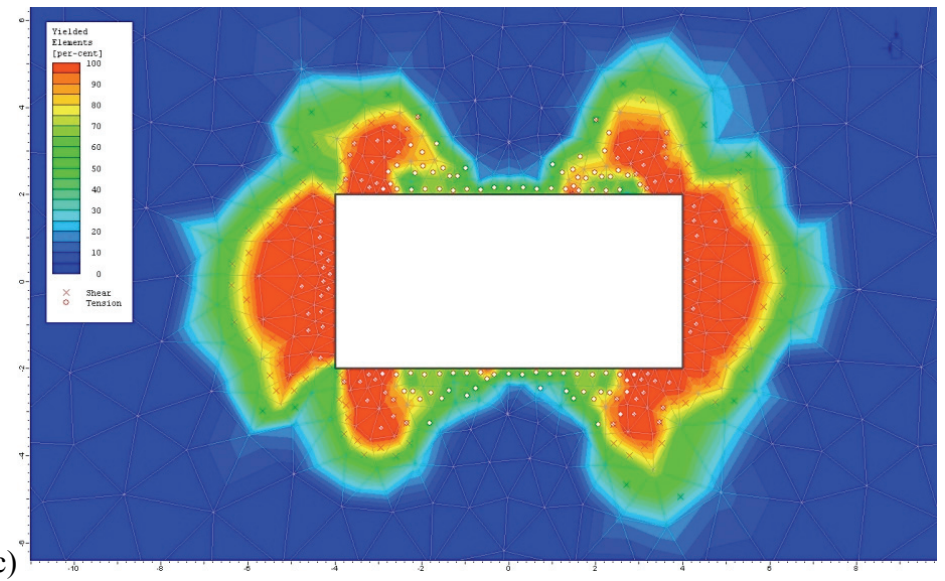

Fig. 2. Deformations around the excavation and adopted safety factor values a) $W S=1.4$, b) $W S=1.0$, c) $W S=0.5$ 
The relationship between the stability factor defined above and parameters considered was examined using the response surface method based on regression analysis and taking into account the assumed criterion with Statistica version 10 software. We have chosen the linear regression because we are looking for the best but the simplest solution to work out the problem in question. It is a rule that in multiple regression analysis the effect on a dependent variable, in this case stability factor, has more than one predictor (independent variable), which is the essential assumption when a lot of parameters need to be considered for working out the solution concerning the general stability factor for underground objects. The regression equation takes the form of the following first-degree polynomial [3]

$$
Y=a+b_{1} \cdot X_{1}+b_{2} \cdot X_{2}+\cdots b_{p} \cdot X_{p}+\varepsilon
$$

where

$a$ - intercept,

$b-$ weight (regression coefficient),

$X$ - parameter,

$\varepsilon-$ random variable of estimation error.

We analysed the correlation between the stability factor and parameters considered to find out the possible relationships between them. According to the obtained correlation matrix it turned out that cohesion and angle of friction have the biggest influence on stability factor value, for which correlation coefficients were equal to 0.526 and 0.422 , respectively. Based on the information obtained, it can be said that these two parameters will have the greatest impact on the results of the analysis. This should also be taken into account during planning further experiments leading ultimately to derivation of the final function characterizing the direct relation between stability of underground objects and selected geotechnical and mining parameters.

Table 3

Correlation matrix with parameters adopted for regression analysis

\begin{tabular}{|c|c|c|c|c|c|}
\hline & $\phi$ & $c$ & $\sigma_{t}$ & $S$ & $W S$ \\
\hline$\phi$ & 1 & 0 & 0 & 0 & 0.422 \\
\hline$c$ & 0 & 1 & 0 & 0 & 0.526 \\
\hline$\sigma_{t}$ & 0 & 0 & 1 & 0 & 0.042 \\
\hline$S$ & 0 & 0 & 0 & 1 & -0.042 \\
\hline$W S$ & 0.422 & 0.526 & 0.042 & -0.042 & 1 \\
\hline
\end{tabular}

The fact of the greatest influence of cohesion and angle of internal friction is reflected in the values of the regression coefficient with which it is possible to compare the contribution of each independent variable in the prediction of the dependent variable, which in this case is the stability factor. In the first case, a regression analysis 
was performed only for parameters included in Table 3. The obtained coefficient of determination $R^{2}$ was equal to $46 \%$ and found to be unsatisfactory. For this reason, the additional parameter in the form of the product of the cohesion and friction angle values was included. During another multiple regression analysis the following formula for stability factor was derived

$$
\begin{gathered}
W S=0.117+0.0206 \cdot \varphi+0.0405 \cdot c \\
+0.0102 \cdot \sigma_{t}-0.014815 \cdot S-0.000608 \cdot(\varphi \cdot c)+\varepsilon .
\end{gathered}
$$

The standard deviation of $\varepsilon$ is 0.153 . Values of stability factor calculated with the use of the above formula are shown in Table 3 (in the column: WS calculated). It should be noted that the coefficient of determination $R^{2}$ this time was $72 \%$, which means that $72 \%$ of the initial variation has been reflected by the WS regression, while the remaining $28 \%$ is in the residual variability. On this basis, the quality of fitting model to data is relatively good. It is assumed that the coefficient of determination could be higher if more data and additional parameters were included in the analysis, which would have a significant impact on risk associated with instability of underground excavation represented by the calculation model considered.

Fitted regression model indicates that the relationship between stability factor and cohesion, angle of friction and tensile strength is positive (with an increase of these parameters the stability factor increases as well), while the relationship between WS and the width of excavation, and the product of cohesion and friction angle is negative (the smaller the value of these parameters, the higher the stability factor). Positive relationship between WS and geotechnical parameters is the logical result of the relation between rock strength and stability of underground facilities. Likewise, negative relationship between obtained stability factor and excavation width is not surprising (the smaller the width of the excavation, the less the risk of instability).

Table 4

Results of analysis

\begin{tabular}{|c|c|c|c|c|c|c|c|c|}
\hline & $\begin{array}{c}\text { Fitted } \\
W S\end{array}$ & $\begin{array}{c}\text { Calculated } \\
W S\end{array}$ & & $\begin{array}{c}\text { Fitted } \\
W S\end{array}$ & $\begin{array}{c}\text { Calculated } \\
W S\end{array}$ & & $\begin{array}{c}\text { Fitted } \\
W S\end{array}$ & $\begin{array}{c}\text { Calculated } \\
W S\end{array}$ \\
\hline $\mathbf{1}$ & $\mathbf{2}$ & $\mathbf{3}$ & $\mathbf{4}$ & $\mathbf{5}$ & $\mathbf{6}$ & $\mathbf{7}$ & $\mathbf{8}$ & $\mathbf{9}$ \\
\hline S. 1 & 0.5 & 0.684 & S. 28 & 0.5 & 0.698 & S. 55 & 0.5 & 0.713 \\
\hline S. 2 & 0.5 & 0.713 & S. 29 & 0.5 & 0.728 & S. 56 & 0.5 & 0.743 \\
\hline S. 3 & 0.5 & 0.698 & S. 30 & 0.5 & 0.713 & S. 57 & 0.5 & 0.728 \\
\hline S. 4 & 1.4 & 1.508 & S. 31 & 1.4 & 1.523 & S. 58 & 1.4 & 1.537 \\
\hline S. 5 & 1.4 & 1.537 & S. 32 & 1.4 & 1.552 & S. 59 & 1.4 & 1.567 \\
\hline S. 6 & 1.4 & 1.523 & S. 33 & 1.4 & 1.537 & S. 60 & 1.4 & 1.552 \\
\hline S. 7 & 1.4 & 1.096 & S. 34 & 1.4 & 1.111 & S. 61 & 1.4 & 1.125 \\
\hline S. 8 & 1.4 & 1.125 & S. 35 & 1.4 & 1.140 & S. 62 & 1.4 & 1.155 \\
\hline S. 9 & 1.4 & 1.111 & S. 36 & 1.4 & 1.125 & S. 63 & 1.4 & 1.140 \\
\hline
\end{tabular}




\begin{tabular}{|c|c|c|c|c|c|c|c|c|}
\hline $\mathbf{1}$ & $\mathbf{2}$ & $\mathbf{3}$ & $\mathbf{4}$ & $\mathbf{5}$ & $\mathbf{6}$ & $\mathbf{7}$ & $\mathbf{8}$ & $\mathbf{9}$ \\
\hline S. 10 & 1.4 & 1.434 & S. 37 & 1.4 & 1.448 & S. 64 & 1.4 & 1.463 \\
\hline S. 11 & 1.4 & 1.463 & S. 38 & 1.4 & 1.478 & S. 65 & 1.4 & 1.493 \\
\hline S. 12 & 1.4 & 1.448 & S. 39 & 1.4 & 1.463 & S. 66 & 1.4 & 1.478 \\
\hline S. 13 & 1.4 & 1.358 & S. 40 & 1.4 & 1.373 & S. 67 & 1.4 & 1.388 \\
\hline S. 14 & 1.4 & 1.388 & S. 41 & 1.4 & 1.402 & S. 68 & 1.4 & 1.417 \\
\hline S. 15 & 1.4 & 1.373 & S. 42 & 1.4 & 1.388 & S. 69 & 1.4 & 1.402 \\
\hline S. 16 & 1.4 & 1.396 & S. 43 & 1.4 & 1.411 & S. 70 & 1.4 & 1.425 \\
\hline S. 17 & 1.4 & 1.425 & S. 44 & 1.4 & 1.440 & S. 71 & 1.4 & 1.455 \\
\hline S. 18 & 1.4 & 1.411 & S. 45 & 1.4 & 1.425 & S. 72 & 1.4 & 1.440 \\
\hline S. 19 & 1 & 1.059 & S. 46 & 1 & 1.073 & S. 73 & 1 & 1.088 \\
\hline S. 20 & 1 & 1.088 & S. 47 & 1.4 & 1.103 & S. 74 & 1.4 & 1.118 \\
\hline S. 21 & 1 & 1.073 & S. 48 & 1.4 & 1.088 & S. 75 & 1.4 & 1.103 \\
\hline S. 22 & 1.4 & 1.433 & S. 49 & 1.4 & 1.448 & S. 76 & 1.4 & 1.463 \\
\hline S. 23 & 1.4 & 1.463 & S. 50 & 1.4 & 1.477 & S. 77 & 1.4 & 1.492 \\
\hline S. 24 & 1.4 & 1.448 & S. 51 & 1.4 & 1.463 & S. 78 & 1.4 & 1.477 \\
\hline S. 25 & 1.4 & 1.246 & S. 52 & 1.4 & 1.261 & S. 79 & 1.4 & 1.275 \\
\hline S. 26 & 1.4 & 1.275 & S. 53 & 1.4 & 1.290 & S. 80 & 1.4 & 1.305 \\
\hline S. 27 & 1.4 & 1.261 & S. 54 & 1.4 & 1.275 & S. 81 & 1.4 & 1.290 \\
\hline
\end{tabular}

The basic assumption of multiple regression analysis is a linear relationship between assumed parameters in the equation, and that residuals are normally distributed [16]. On the basis of normality test chart we tried to verify this condition.

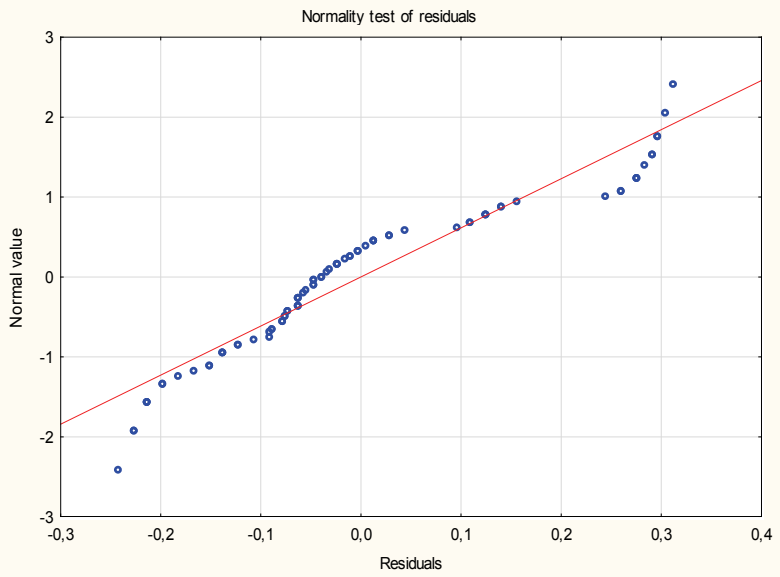

Fig. 3. Normality test of residuals

Random measurement errors are often modelled using a normal distribution. Total number of random measurement errors (negative and positive) should have a distribution close to normal, as a result of the central limit theorem [13]. In the above chart points are localised near the expected normality line but it is still uncertain whether the residuals 
are normally distributed. Additionally, the null hypothesis, that a sample in the form of residuals is normally distributed, was tested using nonparametric Kolmogorov-Smirnov and Shapiro-Wilk tests. The Kolmogorov-Smirnov statistic, $D$, is the maximum value of the difference between cumulative distribution of the sample and assumed distribution function, and the Shapiro-Wilk statistic, $W$, is the ratio of the best estimator of the variance to the usual corrected sum of squares estimator of the variance [16].

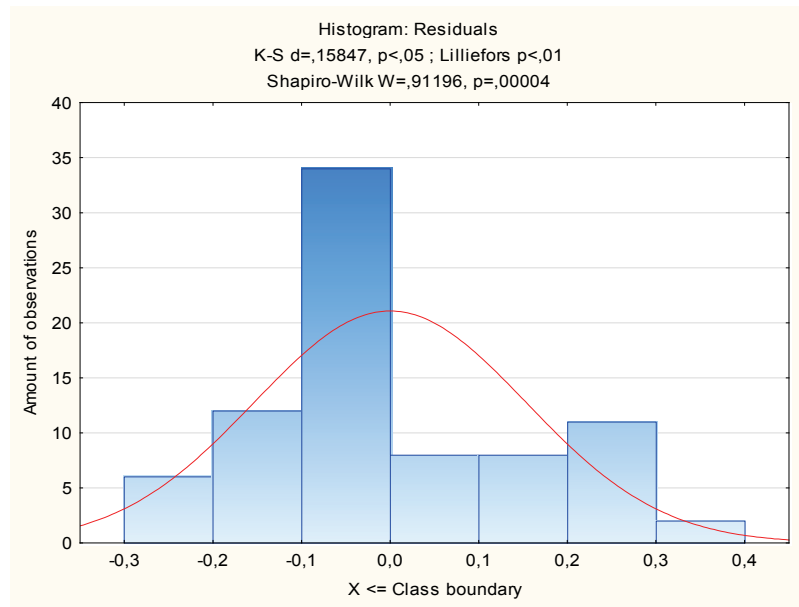

Fig. 4. Normality test of residuals

Even though the obtained determination coefficient value, $R^{2}$, indicates a relatively good quality of regression model fitting to data, the normality of residuals condition is not fulfilled because based on two normality test results (probability less than assumed significance level $\alpha=0.05$ ) it leads to rejection of the null hypothesis. Due to that, the further analysis will be prepared using a different criterion of failure. In that case, if all conditions connected with reliability of regression model fitting are fulfilled, the criterion developed will be assumed as appropriate one. In this situation, further analysis will be conducted using additional assumptions on parameters tested and based on one invariable criterion of instability.

\section{SUMMARY AND CONCLUSIONS}

In order to assess the impact of parameter uncertainty on the excavation stability we used the response surface method. The impact of parameters variability on risk connected with instability of underground excavations was tested using subsequent combinations of geomechanical parameters and width of the excavation values. The criterion of loss of stability was assumed in accordance with the failure zone size 
around the excavation as a result of shear and tensile stresses influence. Based on the results obtained, it was found that the friction angle and cohesion have the greatest effect on the stability factor, and the relationship between the parameters is positive (with an increase in the parameters stability factor increases as well). Defined formula for stability factor was obtained with $72 \%$ coefficient of determination, $R^{2}$ but did not fulfil the condition that residuals have to be normally distributed. On that basis, we decided to change the criterion of instability in further analysis to enhance the chance of fulfilling assumptions associated with reliability of regression model fitting.

The statistical approach proposed, based on response surface method, was found to be suitable for handling the problem of the risk of underground excavation instability. As is known a number of elements that can be called in this case the risk factors affect this phenomenon. The geological structure of the rock mass can by far be considered as one of them. The impact of individual factors on the final result of stability assessment has not yet been fully recognized. Selection of appropriate parameters involving the gradual integration of the subsequent elements to the analysis and study of their impact on the final result may allow us to optimize the process of instability phenomenon assessment, which should be treated as random. The most important in this case is assumption about the number of appropriate parameters for analyses, which have significant meaning in terms of the stability problem.

Due to the complexity of the underground excavation stability issue, the problem of defining a representative factor of stability will be analysed further using additional assumptions. This work will be able to be part of the risk assessment process of large underground caverns conducted in the EU LAGUNA-LBNO project associated with the preparation and feasibility study of underground infrastructure for astrophysical research.

\section{REFERENCES}

[1] Bauer J., PuŁa W., WyjadŁowski M., Schleiss M., Analysis of displacements of horizontally loaded pile group placed in elastic subsoil with random properties, Górnictwo i Geoinżynieria, 2011, Vol. 35, No 2, 79-88, (in Polish).

[2] Bauer J., Kozubal J., PuŁa W., WyjadŁowski M., Probabilistic assessment of pile head displacements under lateral load, Zeszyty Naukowe Politechniki Rzeszowskiej, Budownictwo i Inżynieria Środowiska, 2011, Vol. 58, No 3/II, 17-24, (in Polish).

[3] Carley K.M., Kamneva N.Y., Reminga J., Response Surface Methodology, Centre for Computational Analysis of Social and Organizational Systems (CASOS) Technical Report, 2004.

[4] CHudek M., DuŻy S., Geotechnical problems with maintaining excavations in complex geological and mining conditions, Górnictwo i Geoinżynieria, 2005, Vol. 3, No. 1, 157-164, (in Polish).

[5] DuŻY S., Identification of random capacity parameters of rock massive influence on mining excavations support, Zeszyty Naukowe Politechniki Śląskiej, Górnictwo, 2003, Vol. 258, 79-88, (in Polish).

[6] DuŻy S., Probabilistic analysis of underground excavations stability, Przegląd Górniczy, 2004, Vol. 60, No. 4, 33-38, (in Polish). 
[7] DuŻY S., Random character of processes occurring in the strata subjected to the influences of mining works, Wiadomości Górnicze, 2009, Vol. 60, No. 2, 78-88, (in Polish).

[8] Delventhal K.M., Kissner A., Kulick M., Compendium. Mathematics, Grupa Wydawnicza Berelsmann Media, Horyzont 2002, (in Polish).

[9] GALIŃSKI A., An example analysis of relationship between geo-parameters of deposit rock and surrounding one regarding chosen zones of LGOM mines, Górnictwo i Geoinżynieria, 2009, Vol. 1, 187-193, (in Polish).

[10] HoEK E., In situ and induced stress, Hoek's corner (www.rocscience.com).

[11] Mollon G., Dias D., Soubra A.-H., Probabilistic analysis of circular tunnels in homogeneous soil using Response Surface Methodology, Journal of Geotechnical and Geoenvironmental Engineering, 2009, 1314-1325.

[12] PyteL W., Technical and geomechanical aspects of the main detector cavern's excavation for an underground astrophysical laboratory located in the Polkowice-Sieroszowice mine, Górnictwo i Geoinżynieria, 2011, Vol. 2, 493-500, (in Polish).

[13] SNOPKOWSKI R., Functions of random variables - possibility of reduction of stochastic models, Part 2, Górnictwo i Geoinżynieria, 2005, Vol. 3, 51-61, (in Polish).

[14] Szwedzicki T., Precursors to rock mass failure in underground mines, Archives of Mining Sciences, 2008, Vol. 53, No. 3, 449-465.

[15] Zangeneh N., Azizian A., Lye L., Popescu R., Application of Response Surface Methodology in numerical geotechnical analysis, Conference Paper, 55th Canadian Society for Geotechnical Conference, Ontario, Hamilton 2002.

[16] StatSoft Electronic Statistics Textbook (http://www.statsoft.pl/textbook/stathome.html), (in Polish). 